\title{
Fuzzy Control of Dynamic Positioning Systems for Ships
}

Wen-Jer Chang

Professor, Department of Marine Engineering, National Taiwan Ocean University, Keelung 202, Taiwan, R.O.C.

Guo-Jang Chen

Student, Department of Marine Engineering, National Taiwan Ocean University, Keelung 202, Taiwan, R.O.C.

Yi-Lin Yeh

Student, Department of Marine Engineering, National Taiwan Ocean University, Keelung 202, Taiwan, R.O.C.

Follow this and additional works at: https://jmstt.ntou.edu.tw/journal

Part of the Engineering Commons

\section{Recommended Citation}

Chang, Wen-Jer; Chen, Guo-Jang; and Yeh, Yi-Lin (2002) "Fuzzy Control of Dynamic Positioning Systems for Ships," Journal of Marine Science and Technology. Vol. 10: Iss. 1, Article 7.

DOI: $10.51400 / 2709-6998.2300$

Available at: https://jmstt.ntou.edu.tw/journal/vol10/iss1/7

This Research Article is brought to you for free and open access by Journal of Marine Science and Technology. It has been accepted for inclusion in Journal of Marine Science and Technology by an authorized editor of Journal of Marine Science and Technology. 


\section{Fuzzy Control of Dynamic Positioning Systems for Ships}

\section{Acknowledgements}

The authors would like to thank two anonymous referees for their constructive comments and suggestions which have made substantial improvements on this paper. Besides, this work was supported by the National Science Council of the Republic of China under Contract NSC90-2213-E-019-014. 


\title{
FUZZY CONTROL OF DYNAMIC POSITIONING SYSTEMS FOR SHIPS
}

\author{
Wen-Jer Chang*, Guo-Jang Chen**, and Yi-Lin Yeh**
}

Key words: Dynamic positioning systems, fuzzy control, Takagi-Sugeno fuzzy model, parallel distributed compensation.

\begin{abstract}
In this paper we consider the control problem of Dynamic Positioning Systems for Ships (DPSS). It interests as a case which study in nonlinear controller design because the model exhibits nonlinear interaction in three degrees of freedom (surge, sway, and yaw) by means of main propellers aft of the ship. The DPSS system considered in this paper is modeled by a Takagi-Sugeno (T-S) type fuzzy model. By using linear feedback controller design technology, we design a nonlinear fuzzy controller for the T-S type fuzzy-based DPSS. Finally, simulation results show the utility of the present fuzzy control methodology.
\end{abstract}

\section{INTRODUCTION}

Recently, the nonlinear control problem of Dynamic Positioning Systems for Ships (DPSS) has been widely studied [1-4]. The DPSS control problem is usually solved under the assumption that the kinematic equations can be linearized about a constant yaw angle such that linear theory and gain scheduling techniques can be applied. This assumption has been removed by using the Globally Exponentially Stable (GES) nonlinear control law, which is developed in [2]. The GES is proven by applying the backstepping design methodology based on the Lyapunov stability theory. The control law is simulated on thruster-controlled ships [2]. In this paper, we utilize Linear Matrix Inequality (LMI) methodology [5-8] to find a fuzzy controller for stabilizing the nonlinear DPSS.

Using fuzzy control methods to control nonlinear DPSS, we utilize T-S type fuzzy model to represent the nonlinear DPSS. The T-S fuzzy type model are described by a set of fuzzy IF-THEN rules, and then local

Paper Received Dec. 6, 2001. Author for Correspondence: Wen-Jer Chang. *Professor, Department of Marine Engineering, National Taiwan Ocean University, Keelung 202, Taiwan, R.O.C.

**Student, Department of Marine Engineering, National Taiwan Ocean University, Keelung 202, Taiwan, R.O.C. dynamic in the different state space can be regard as the linear system. The controller of nonlinear system can be blended by the linear controllers of all rules. The controller design is carried out depend on the fuzzy model via the Parallel Distributed Compensation (PDC), which has been proposed in [6-7, 9-13]. The PDC concept is useful for the fuzzy controller design of T-S type fuzzy models. The control approach is to design linear feedback gains for each local linear model and let the overall system input can be blended by these linear feedback gains. Based on LMI methods, we can find a suitable common positive definite matrix and linear feedback gains for each rule, and then to satisfy the stability conditions for closed-loop systems.

The organization of this paper is presented as follows: Section 2 describes the dynamic equations of the nonlinear DPSS and the T-S type fuzzy modeling of the DPSS. Section 3 will provide the stability conditions for the existence of the T-S fuzzy controllers, which achieve the stability of the overall DPSS. The simulated results are also stated in this section. Finally, a conclusion is given in the Section 4.

\section{T-S TYPE FUZZY MODELLING OF THE NONLINEAR DPSS}

The normalized DPSS system model is proposed in [1]. The case study of this paper is benchmark DPSS system [2], which is controlled exclusively by means of thrusters. If thruster-assisted mooring is to be considered, the ship can also be supplied with anchors. During DPSS the damping forces can be assumed to be linear since the speed of the ship is quite small. Therefore the equations of motion are as follow:

$$
\begin{aligned}
& \dot{\eta}=\mathbf{J}(\boldsymbol{\eta}) v \\
& \dot{v}=\mathbf{H}_{\mathbf{1}} \eta+\mathbf{H}_{\mathbf{2}} v+\mathbf{H}_{\mathbf{3}} \tau
\end{aligned}
$$

where $\mathbf{H}_{\mathbf{1}}$ is state matrix of the earth-fixed positions and yaw angle $\psi$ of the vessel, $\mathbf{H}_{2}$ is the state matrix of the body-fixed velocities, and $\mathbf{H}_{3}$ is the state matrix of the 
control force and moment which are provided by the thruster system.

$$
\mathbf{J}(\boldsymbol{\eta})=\left[\begin{array}{ccc}
\cos (\psi) & -\sin (\psi) & 0 \\
\sin (\psi) & \cos (\psi) & 0 \\
0 & 0 & 1
\end{array}\right]
$$

is the rotation matrix in yaw and

$$
\begin{aligned}
& \mathbf{H}_{\mathbf{1}} \equiv-\mathbf{N}^{-\mathbf{1}} \mathbf{T} \equiv\left[\begin{array}{lll}
h_{1_{11}} & h_{1_{12}} h_{1_{13}} \\
h_{1_{21}} h_{1_{22}} h_{1_{23}} \\
h_{1_{31}} h_{1_{32}} h_{1_{33}}
\end{array}\right] \\
& \mathbf{H}_{\mathbf{2}} \equiv-\mathbf{N}^{-\mathbf{1}} \mathbf{Q} \equiv\left[\begin{array}{lll}
h_{2_{11}} & h_{212} h_{2_{13}} \\
h_{221} & h_{22} h_{2_{23}} \\
h_{231} & h_{2_{32}} h_{2_{31}}
\end{array}\right] \\
& \mathbf{H}_{\mathbf{3}} \equiv \mathbf{N}^{\mathbf{- 1}} \equiv\left[\begin{array}{lll}
h_{3_{11}} & h_{3_{12}} h_{3_{13}} \\
h_{3_{21}} & h_{3_{22}} h_{3_{23}} \\
h_{3_{31}} & h_{3_{32}} h_{3_{33}}
\end{array}\right]
\end{aligned}
$$

The earth-fixed positions $(x, y)$ and yaw angle $\psi$ of the ships is expressed in vector $\eta=\left[\begin{array}{lll}x & y & \psi\end{array}\right]^{T}$. The bodyfixed velocities are represent by the vector $v=\left[\begin{array}{ll}u & v r\end{array}\right]^{T}$, where the elements in these state vectors describes the surge, sway and yaw modes, respectively. The control and moment are provided by the thruster system, $\tau=\left[\tau_{1}\right.$ $\left.\tau_{2} \tau_{3}\right]^{T}$, see [1] for details. The matrices $\mathbf{N}, \mathbf{Q}$ and $\mathbf{T}$ for a floating production ship are given in Section 3. Starboard-port symmetry of ships implies that $\mathbf{N}$ and $\mathbf{Q}$, which is constructed as follow:

$$
\mathbf{N}=\left[\begin{array}{ccc}
n_{11} & 0 & 0 \\
0 & n_{22} n_{23} \\
0 & n_{32} n_{33}
\end{array}\right], \mathbf{Q}=\left[\begin{array}{ccc}
q_{11} & 0 & 0 \\
0 & q_{22} q_{23} \\
0 & q_{32} q_{33}
\end{array}\right]
$$

The $\mathbf{N}$ is the inertia matrix including hydrodynamic added inertia. In general $\mathbf{N}$ will be nonsymmetrical, that is $n_{23} \neq n_{32}$ due to the properties of hydrodynamic added inertia [1]. The $\mathbf{Q}$ is damping matrix, which is nonsymmetrical in most cases.

In other words, there is no coupling between the surge and the sway-yaw subsystems. The anchor forces and moment are usually described by a diagonal matrix as follows:

$$
\mathbf{T}=\left[\begin{array}{ccc}
t_{11} & 0 & 0 \\
0 & t_{22} & 0 \\
0 & 0 & t_{33}
\end{array}\right]
$$

After combining (1) and (2) in the space of state variables, we can obtain the following state equation:

$$
\begin{aligned}
\dot{x}_{1} & =\cos \left(x_{3}\right) x_{4}-\sin \left(x_{3}\right) x_{5} \\
\dot{x}_{2} & =\sin \left(x_{3}\right) x_{4}-\cos \left(x_{3}\right) x_{5} \\
\dot{x}_{3} & =x_{6} \\
\dot{x}_{4} & =h_{111} x_{1}+h_{1_{12}} x_{2}+h_{113} x_{3}+h_{211} x_{4}+h_{212} x_{5} \\
& +h_{213} x_{6}+h_{3_{11}} u_{1}+h_{312} u_{2}+h_{313} u_{3} \\
\dot{x}_{5} & =h_{1_{21}} x_{1}+h_{1_{22}} x_{2}+h_{1_{23}} x_{3}+h_{2_{21}} x_{4}+h_{22} x_{5} \\
& +h_{223} x_{6}+h_{3_{21}} u_{1}+h_{3_{22}} u_{2}+h_{3_{23}} u_{3} \\
\dot{x}_{6} & =h_{1_{31}} x_{1}+h_{1_{32}} x_{2}+h_{1_{33}} x_{3}+h_{2_{31}} x_{4}+h_{232} x_{5} \\
& +h_{233} x_{6}+h_{331} u_{1}+h_{332} u_{2}+h_{333} u_{3}
\end{aligned}
$$

where

$$
\begin{aligned}
& x(t)=\left[\begin{array}{llllll}
x_{1} & x_{2} & x_{3} & x_{4} & x_{5} & x_{6}
\end{array}\right]^{T}=\left[\begin{array}{llllll}
x & y & \psi & u & v & r
\end{array}\right]^{T}(8) \\
& u(t)=\left[\begin{array}{lll}
u_{1} & u_{2} & u_{3}
\end{array}\right]^{T}=\left[\begin{array}{lll}
\tau_{1} & \tau_{2} & \tau_{3}
\end{array}\right]^{T}
\end{aligned}
$$

We transform the nonlinear DPSS into T-S type fuzzy model and we assume that yaw angle changes between $x_{3} \in\left( \pm \frac{\pi}{2}\right)$. Then the DPSS T-S type fuzzy model forms as follows:

Rule $^{1}$ : IF $x_{3}$ is about 0

$$
\text { THEN } \dot{x}(t)=\mathbf{A}_{1} x(t)+\mathbf{B}_{1} u(t)
$$

Rule $^{2}:$ IF $x_{3}$ is about $\frac{\pi}{2} \quad\left(\left|x_{3}\right|<\frac{\pi}{2}\right)$

THEN $\dot{x}(t)=\mathbf{A}_{2} x(t)+\mathbf{B}_{2} u(t)$

Rule $^{3}:$ IF $x_{3}$ is about $-\frac{\pi}{2} \quad\left(\left|x_{3}\right|<\frac{\pi}{2}\right)$

THEN $\dot{x}(t)=\mathbf{A}_{3} x(t)+\mathbf{B}_{3} u(t)$

where

$$
\mathbf{A}_{1}=\left[\begin{array}{cccccc}
0 & 0 & 0 & 1 & -\alpha & 0 \\
0 & 0 & 0 & \alpha & 1 & 0 \\
0 & 0 & 0 & 0 & 0 & 1 \\
h_{1_{11}} & h_{1_{12}} h_{1_{13}} & h_{2_{11}} h_{212} h_{2_{13}} \\
h_{1_{21}} & h_{1_{22}} h_{1_{23}} h_{2_{21}} h_{2_{22}} h_{2_{23}} \\
h_{1_{31}} & h_{1_{32}} h_{1_{33}} h_{2_{31}} h_{2_{32}} h_{233}
\end{array}\right]
$$

$$
\mathbf{A}_{2}=\left[\begin{array}{cccccc}
0 & 0 & 0 & \beta & -1 & 0 \\
0 & 0 & 0 & 1 & \beta & 0 \\
0 & 0 & 0 & 0 & 0 & 1 \\
h_{1_{11}} & h_{1_{12}} & h_{1_{13}} & h_{2_{11}} h_{212} h_{213} \\
h_{1_{21}} & h_{1_{22}} h_{1_{23}} h_{2_{21}} h_{22} h_{2_{23}} \\
h_{1_{31}} & h_{1_{32}} h_{1_{33}} h_{2_{31}} h_{2_{32}} h_{2_{33}}
\end{array}\right]
$$




$$
\begin{aligned}
& \mathbf{A}_{3}=\left[\begin{array}{cccccc}
0 & 0 & 0 & \beta & 1 & 0 \\
0 & 0 & 0 & -1 & \beta & 0 \\
0 & 0 & 0 & 0 & 0 & 1 \\
h_{111} & h_{1_{12}} & h_{113} & h_{211} & h_{212} & h_{213} \\
h_{1_{21}} & h_{1_{22}} & h_{123} & h_{221} & h_{222} & h_{223} \\
h_{1_{31}} & h_{1_{32}} & h_{1_{33}} & h_{231} & h_{232} & h_{233}
\end{array}\right] \\
& \mathbf{B}_{1}=\mathbf{B}_{2}=\mathbf{B}_{3}=\left[\begin{array}{lllll}
0 & 0 & 0 & h_{3_{11}} h_{3_{21}} h_{331} \\
0 & 0 & 0 & h_{3_{12}} h_{3_{22}} h_{3_{32}} \\
0 & 0 & 0 & h_{3_{13}} h_{323} h_{3_{33}}
\end{array}\right]
\end{aligned}
$$

in which $\alpha=\sin \left(2^{\circ}\right)$ and $\beta=\cos \left(88^{\circ}\right)$. The above T-S type fuzzy model can be represented as:

$$
\dot{x}(t)=\frac{\sum_{i=1}^{3} \omega_{i}\left[\mathbf{A}_{\mathbf{i}} \mathbf{x}(t)+\mathbf{B}_{\mathbf{i}} \mathbf{u}(t)\right]}{\sum_{i=1}^{3} \omega_{i}}
$$

where

$$
\omega_{i}(t)=\prod_{j=1}^{6} M_{i j}\left(x_{j}(t)\right)
$$

and $M_{i j}\left(x_{j}(t)\right)$ is the grade of membership of $x_{j}(t)$ in $M_{i j}$, $\omega_{i}(t)$ is the weight of the $i$-th rule and it is appropriate for membership values. The membership functions of this T-S type fuzzy DPSS are shown in Fig. 1.

\section{T-S TYPE FUZZY CONTROLLER DESIGN FOR THE FUZZY-BASED DPSS}

We first changed the nonlinear DPSS into the T-S type fuzzy model in the Section 2. In this section, we will introduce the fuzzy controller design of the T-S type fuzzy models for the DPSS. From the concept of PDC, we first need to design the linear controller for each rule, and then the controller of nonlinear system can be blended by the linear controllers of all rules. Using the PDC concept, the fuzzy controller is represented as follows:

Rule $^{1}$ : IF $x_{3}$ is about 0

THEN $u(t)=\mathbf{G}_{1} x(t)$

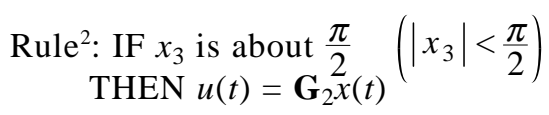

Rule $^{3}$ : IF $x_{3}$ is about $-\frac{\pi}{2} \quad\left(\left|x_{3}\right|<\frac{\pi}{2}\right)$
THEN $u(t)=\mathbf{G}_{3} x(t)$

where $\mathbf{G}_{1}, \mathbf{G}_{2}$ and $\mathbf{G}_{3}$ are the desired feedback gains for the fuzzy controller design. Hence, the output of the fuzzy controller is

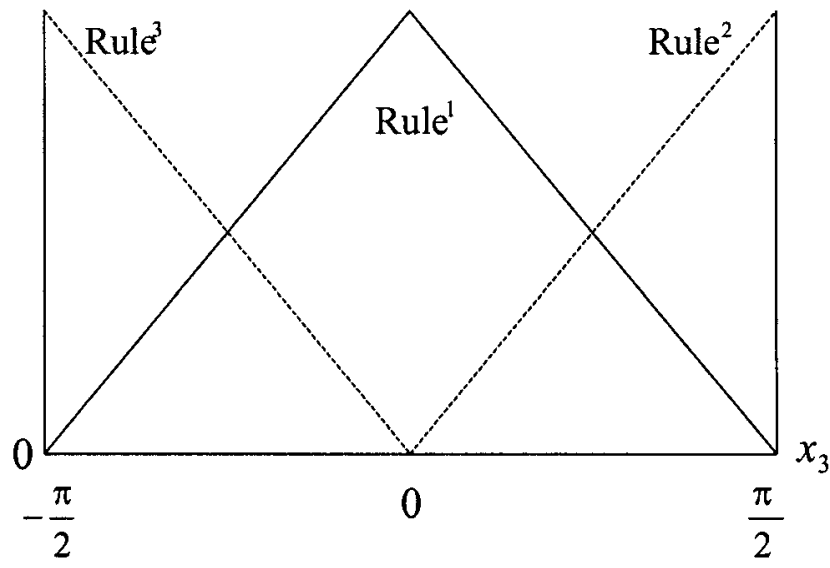

Fig. 1. The membership functions of $x_{3}(t)$.

$$
u(t)=\frac{\sum_{i=1}^{3} \omega_{i}\left[\mathbf{G}_{\mathbf{i}} x(t)\right]}{\sum_{i=1}^{3} \omega_{i}}
$$

Substituting (15) into (12), we can obtain the closed-loop state equation as follows:

$$
\dot{x}(t)=\frac{\sum_{i=1}^{3} \sum_{j=1}^{3} \omega_{i}(t) \omega_{j}(t)\left\{\left(\mathbf{A}_{\mathbf{i}}+\mathbf{B}_{\mathbf{i}} \mathbf{G}_{\mathbf{j}}\right) x(t)\right\}}{\mathbf{W}}
$$
$\begin{aligned} & \text { where } \mathbf{W} \\ & \text { we obtain }\end{aligned}=\sum_{i=1}^{3} \sum_{j=1}^{3} \omega_{i}(t) \omega_{j}(t)$. Rewriting equation (16),

$\dot{x}(t)=\frac{1}{\mathbf{W}}\left[\sum_{i=1}^{3} \omega_{i}(t) \omega_{i}(t)\left(\mathbf{A}_{i}+\mathbf{B}_{i} \mathbf{G}_{i}\right) x(t)+2 \sum_{i<j} \omega_{i}(t) \omega_{j}(t) \mathbf{R}_{i j} x(t)\right]$

where

$$
\mathbf{R}_{\mathrm{ij}}=\frac{\left(\mathbf{A}_{i}+\mathbf{B}_{i} \mathbf{G}_{j}\right)+\left(\mathbf{A}_{j}+\mathbf{B}_{j} \mathbf{G}_{i}\right)}{2} i<j
$$

Note that $\mathbf{R}_{\mathrm{ij}}$ denotes the influence item between each other rule, which in the same range in membership function.

The stability analysis of the closed-loop T-S type fuzzy model, which is driven by the PDC-type fuzzy controller, is quoted in [6,9-13].

\section{Lemma 1 [6]}

The DPSS T-S type fuzzy model is asymptotic stable in the large if there exists a common positive definite matrix $\mathbf{P}$ such that the following two conditions are satisfied.

$$
\left(\mathbf{A}_{i}+\mathbf{B}_{i} \mathbf{G}_{i}\right)^{T} \mathbf{P}+\mathbf{P}\left(\mathbf{A}_{i}+\mathbf{B}_{i} \mathbf{G}_{i}\right)<0, \quad i=1,2,3
$$




$$
\mathbf{R}_{i j}{ }^{T} \mathbf{P}+\mathbf{P} \mathbf{R}_{i j}<0, \quad i<j<3
$$

The stability analysis of T-S type fuzzy system depends on the common positive definite matrix $\mathbf{P}$ and linear feedback gains $\mathbf{G}_{i}$. Most of procedures are developed to find the suitable $\mathbf{P}$ and $\mathbf{G}_{i}$ to satisfy (19) and (20) by iterative methods. In This paper, we will use the LMI methodology to deal with the present problem.

It is assumed that there is a linear matrix inequality (LMI) of the following form:

$$
\mathbf{G}(z)=\mathbf{G}_{0}+\sum_{i=1}^{m} z_{i} \mathbf{G}_{i}>0
$$

where $z^{T}=\left(\begin{array}{llll}z_{1} & z_{1} & \ldots & z_{m}\end{array}\right)$ is the variable and the symmetric matrices $\mathbf{G}_{i}=\mathbf{G}_{i}^{T} \in \mathbf{R}^{n \times n}, i=0, \ldots, m$ are given. The inequality symbol $>0$ means that $\mathbf{G}(z)$ is positive definite. Considering (21), the purpose of LMI methodology is to find $z$ such that $\mathbf{G}(z)>0$ or the LMI is infeasible.

The LMI (21) is a convex constraint on $z$, i.e., the set $\{z \mid \mathbf{G}(z)>0\}$ is convex. In the control theory, many stability conditions can be transformed into a LMI form, such as Lyapunov inequality. The Lyapunov inequality for continuous-time system has the following form:

$$
\mathbf{A}^{T} \mathbf{P}+\mathbf{P A}<0
$$

In this paper, the stability conditions for the nonlinear controller design problem of DPSS have been stated in (19) and (20). Fortunately, (19) and (20) can be transformed into a LMI if we assign $\mathbf{G}_{i}=\mathbf{K}_{i} \mathbf{P}^{-1}$. Applying the interior point polynomial method [14], we can find the solutions of LMI. The interior point polynomial method [14] has been used to construct a useful package in the LMI-toolbox of MATLAB software. It can easily find the common positive definite matrix $\mathbf{P}$ and linear feedback controllers $\mathbf{G}_{i}$ for each rule for satisfying the sufficient stability conditions (19) and (20).

Now, we will present the numerical simulations for nonlinear DPSS. First, we use the T-S type fuzzy model to represent DPSS. We consider a tanker with system matrices as follows (Bis-scaled values form [1]):

$$
\begin{gathered}
\mathbf{N}=\left[\begin{array}{ccc}
1.0852 & 0 & 0 \\
0 & 2.0575 & -0.4087 \\
0 & -0.4087 & 0.2153
\end{array}\right], \mathbf{Q}=\left[\begin{array}{ccc}
0.0865 & 0 & 0 \\
0 & 0.0762 & 0.151 \\
0 & 0.0151 & 0.0031
\end{array}\right] \\
\mathbf{T}=\left[\begin{array}{ccc}
0.0389 & 0 & 0 \\
0 & 0.0266 & 0 \\
0 & 0 & 0
\end{array}\right]
\end{gathered}
$$

Then, the system matrices of DPSS T-S type fuzzy model have the following forms:

$\mathbf{A}_{1}=\left[\begin{array}{cccccc}0 & 0 & 0 & 1 & -0.0349 & 0 \\ 0 & 0 & 0 & 0.0349 & 1 & 0 \\ 0 & 0 & 0 & 0 & 0 & 1 \\ -0.0358 & 0 & 0 & -0.0797 & 0 & 0 \\ 0 & -0.0208 & 0 & 0 & -0.0818 & -0.1224 \\ 0 & -0.0394 & 0 & 0 & -0.2254 & -0.2468\end{array}\right]$

$$
\mathbf{A}_{2}=\left[\begin{array}{cccccc}
0 & 0 & 0 & 0.0349 & -1 & 0 \\
0 & 0 & 0 & 1 & 0.0349 & 0 \\
0 & 0 & 0 & 0 & 0 & 1 \\
-0.0358 & 0 & 0 & -0.0797 & 0 & 0 \\
0 & -0.0208 & 0 & 0 & -0.0818 & -0.1224 \\
0 & -0.0394 & 0 & 0 & -0.2254 & -0.2468
\end{array}\right]
$$

$$
\mathbf{A}_{3}=\left[\begin{array}{cccccc}
0 & 0 & 0 & 0.0349 & 1 & 0 \\
0 & 0 & 0 & -1 & 0.0349 & 0 \\
0 & 0 & 0 & 0 & 0 & 1 \\
-0.0358 & 0 & 0 & -0.0797 & 0 & 0 \\
0 & -0.0208 & 0 & 0 & -0.0818 & -0.1224 \\
0 & -0.0394 & 0 & 0 & -0.2254 & -0.2468
\end{array}\right]
$$

$$
\mathbf{B}_{1}=\mathbf{B}_{2}=\mathbf{B}_{3}=\left[\begin{array}{cccccc}
0 & 0 & 0 & 0.9215 & 0 & 0 \\
0 & 0 & 0 & 0 & 0.7802 & 1.4811 \\
0 & 0 & 0 & 0 & 1.4811 & 7.4562
\end{array}\right]^{T}
$$

Applying LMI-toolbox of MATLAB, we can find a suitable common positive definite matrix $\mathbf{P}$ and linear feedback controllers $\mathbf{G}_{1}, \mathbf{G}_{2}$ and $\mathbf{G}_{3}$ to satisfying (19) and (20). The solutions can be found as follows:

$\mathbf{P}=\left[\begin{array}{cccccc}80.9059 & 0.0189 & -0.0039 & 78.2630 & 0.1595 & -0.0146 \\ 0.0189 & 91.7172 & -2.3605 & -0.0861 & 123.4075 & -14.6062 \\ -0.0039 & -2.3605 & 88.6713 & -0.0059 & -18.6237 & 70.2996 \\ 78.2630 & -0.0861 & -0.0059 & 142.5254 & 0.0170 & -0.0054 \\ 0.1595 & 123.4075 & -18.6237 & 0.0170 & 261.8519 & -42.5122 \\ -0.0146 & -14.6062 & 70.2996 & -0.0054 & -42.5122 & 94.6172\end{array}\right]$ 
$\mathbf{G}_{1}=\left[\begin{array}{cccccc}-2.5008 & -0.0323 & 0.0013 & -4.0261 & -0.0478 & 0.0059 \\ 0.0242 & -3.7457 & 0.5118 & 0.0276 & -7.4426 & 1.1990 \\ -0.0033 & 0.4926 & -2.0413 & -0.0035 & 1.3251 & -2.5837\end{array}\right]$

(26b)

$\mathbf{G}_{2}=\left[\begin{array}{cccccc}-1.6374 & -1.3577 & 0.0443 & -2.9198 & -1.8310 & 0.2238 \\ 1.4449 & -2.7685 & 0.4458 & 1.4008 & -5.7836 & 0.9781 \\ -0.2507 & 0.3846 & -1.7263 & -0.2429 & 1.0951 & -2.1628\end{array}\right]$

(26c)

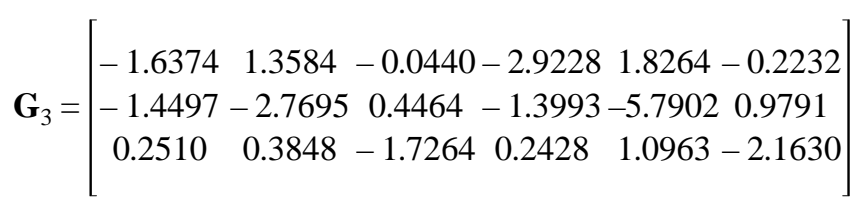

(26d)

Substituting $\mathbf{G}_{1}$ and $\mathbf{G}_{2}$ into (20), we obtain

$\mathbf{P R}_{12}^{T}+\mathbf{R}_{12} \mathbf{P}=\left[\begin{array}{cccccc}0.0057 & -0.0001 & 0 & -0.0016 & 0 & 0 \\ -0.0001 & 0.0047 & -0.0003 & -0.0001 & -0.0009 & 0.0001 \\ 0 & -0.0003 & 0.0008 & 0 & -0.0001 & -0.0004 \\ -0.0016 & -0.0001 & 0 & -0.0004 & 0.0001 & 0 \\ 0 & -0.0009 & -0.0001 & 0.0001 & -0.0003 & 0.0001 \\ 0 & 0.0001 & -0.0004 & 0 & 0.0001 & 0\end{array}\right]$

$$
<0
$$

Substituting $\mathbf{G}_{1}$ and $\mathbf{G}_{3}$ into (20), we obtain

$$
\mathbf{P R}_{13}^{T}+\mathbf{R}_{13} \mathbf{P}=\left[\begin{array}{cccccc}
0.0057 & 0.0001 & 0 & -0.0016 & 0 & 0 \\
0.0001 & 0.0047 & -0.0003 & 0.0001 & -0.0009 & 0.0001 \\
0 & -0.0003 & 0.0008 & 0 & -0.0001 & -0.0004 \\
-0.0016 & 0.0001 & 0 & -0.0004 & -0.0001 & 0 \\
0 & -0.0009 & -0.0001 & -0.0001 & -0.0003 & 0.0001 \\
0 & 0.0001 & -0.0004 & 0 & 0.0001 & 0
\end{array}\right]
$$$$
<0
$$

The above fuzzy controller satisfies the stability conditions (19) and (20). Hence, the DPSS TS-type fuzzy system is stable with the linear feedback gains given in (26).

Using the above control gains for the nonlinear DPSS, we are going to simulate the responses of the body-fixed velocities $v=\left[\begin{array}{lll}u & v & r\end{array}\right]^{\mathrm{T}}$, earth-fixed positions $(x, y)$ and yaw angle $\psi$ of the vessel, respectively. The simulated results are given in Fig. 2 to Fig. 8. From these figures, it has been shown that the sound effect of the LMI-based fuzzy type control method is very remarkable.

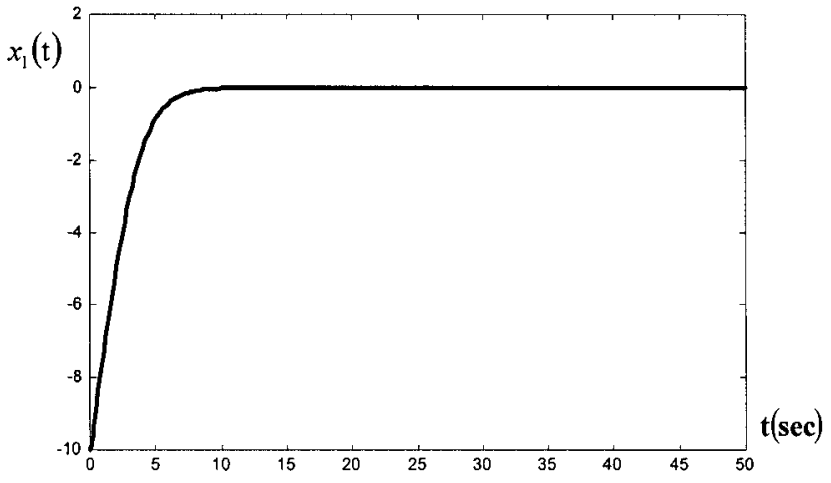

Fig. 2. Measured x-position (m).

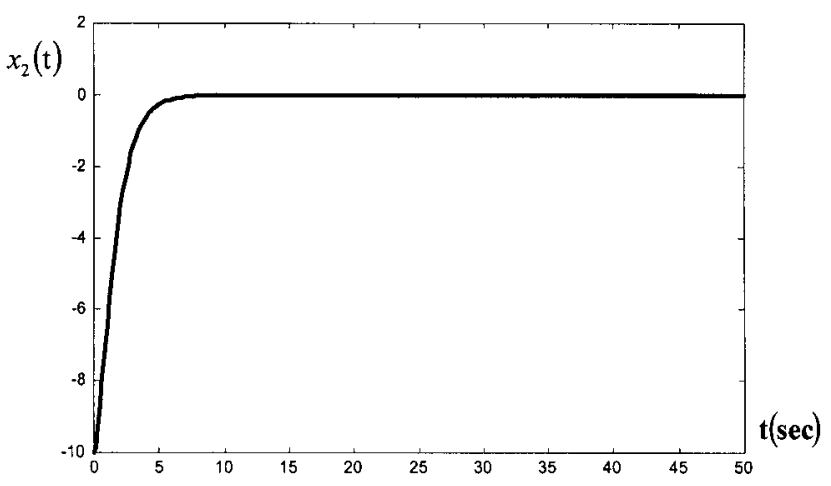

Fig. 3. Measured y-position (m).

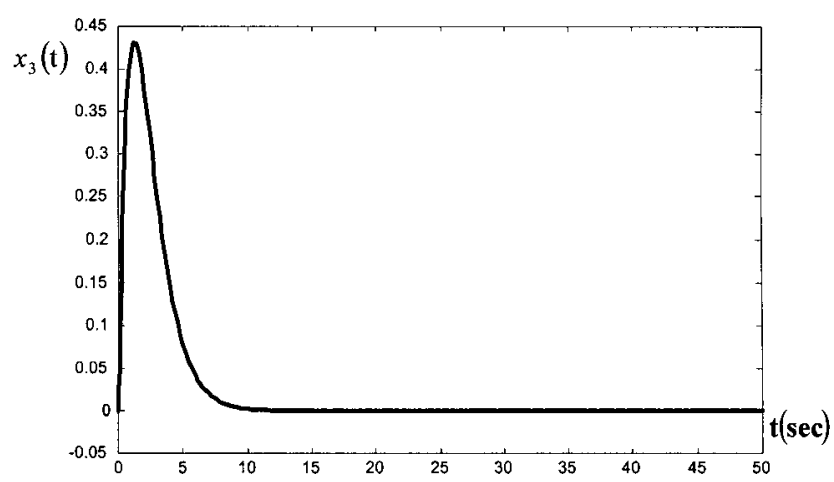

Fig. 4. Measured yaw angle (deg).

\section{CONCLUSIONS}

In this paper, we have used T-S type fuzzy controllers to control the nonlinear DPSS. First, we utilized T$S$ type fuzzy model to represent the nonlinear DPSS. Via PDC concept, we only need to design the linear feedback gain in the each rule, and then the controller of nonlinear system can be blended by the linear control- 


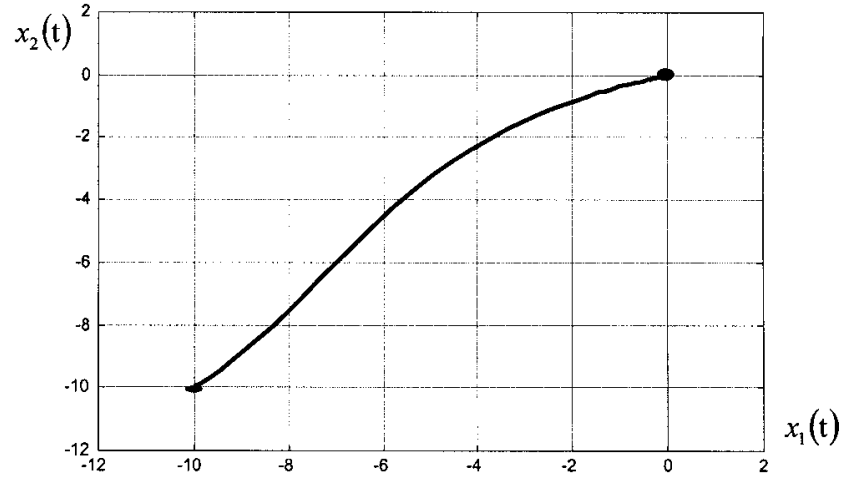

Fig. 5. The xy-plot (m).

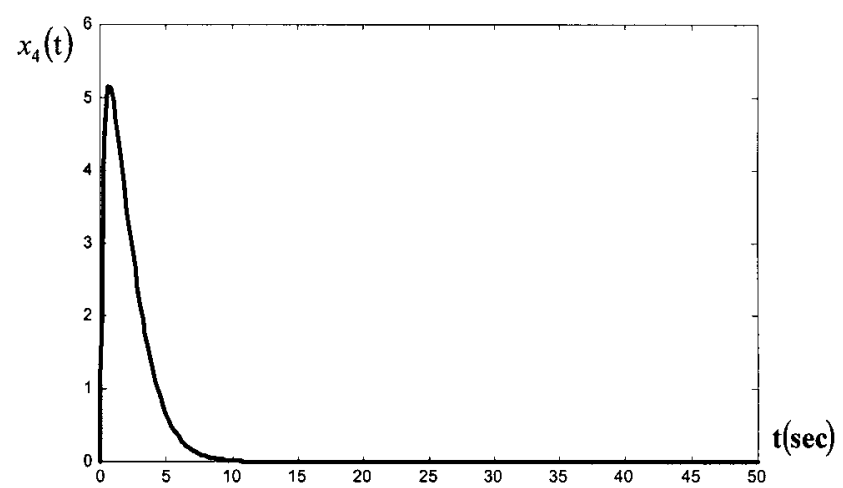

Fig. 6. Surge velocity $(\mathrm{m} / \mathrm{s})$.

lers of all rules. Using LMI tools, we can solve common positive definite matrix $\mathbf{P}$ and linear feedback gains, to satisfy the stability conditions for the T-S type fuzzy DPSS. Finally, the performances of the fuzzy-based DPSS can be realized in the simulated results.

\section{ACKNOWLEDGEMENT}

The authors would like to thank two anonymous referees for their constructive comments and suggestions which have made substantial improvements on this paper. Besides, this work was supported by the National Science Council of the Republic of China under Contract NSC90-2213-E-019-014.

\section{REFERENCES}

1. Fossen, T.I., Guidance and Control of Ocean Vehicles, Wiley, New York (1994).

2. Fossen, T.I. and Grovlen, A., "Nonlinear Output Feedback Control of Dynamically Positioned Ships Using Vectorial Observer Backstepping," IEEE Trans. on Control Systems Technology, Vol. 6, No. 1, pp. 121-128

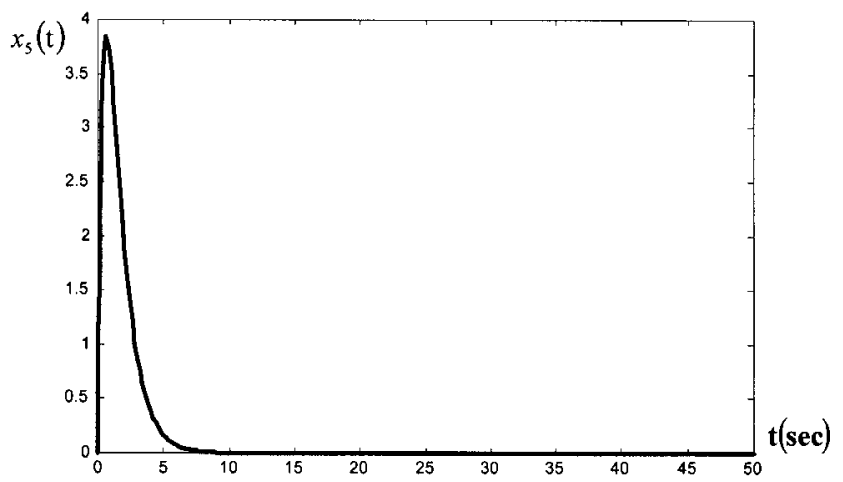

Fig. 7. Sway velocity $(\mathrm{m} / \mathrm{s})$.

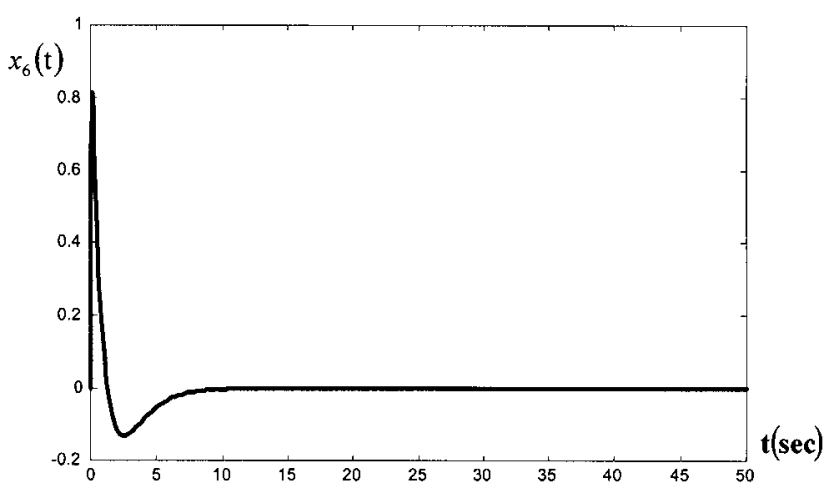

Fig. 8. Yaw velocity $(\mathrm{m} / \mathrm{s})$.

(1998).

3. Godhavn, J.M., Fossen, T.I. and Berge, S.P., "Nonlinear and Adaptive Backstepping Designs for Tracking Control of Ships," Int. J. Adaptive Control and Signal Processing, Vol. 12, No. 8, pp. 649-670 (1998).

4. Pettersen, K.Y. and Nijmeijer, H., "Global Practical Stabilization and Tracking for an Underactuated Ship - A Combined Averaging and Backstepping Approach," Proc. of IFAC Conf. on System Structure and Control, Nantes, France, pp. 59-64 (1998).

5. Boyd, S. et al., Linear Matrix Inequalities in Systems and Control Theory, Philadelphia, PA: SIAM (1994).

6. Tanaka, K., Ikeda, T. and Wang, H.O., "Fuzzy Control System Design via LMIs," Proc. of the American Control Conference, New Mexico, pp. 2873-2877 (1997).

7. Kim, K., Joh, J., Langari, R. and Kwon, W., "LMI-Based Design of T-S Fuzzy Controllers Using Fuzzy Estimator," Proc. of the 38th Conference on Decision \& Control Phoenix, Arizona, USA, pp. 4343-4348 (1999).

8. Kiriakidis, K., "Robust Stabilization of the TakagiSugeno Fuzzy Model via Bilinear Matrix Inequalities," IEEE Trans. Fuzzy System, Vol. 9, No. 2, pp. 269-277 (2001). 
9. Chang, W.J. and Sun, C.C., "Fuzzy Control with Common Observability Gramian Assignment for Continuous Takagi-Sugeno Models," Proc. of the 1999 American Control Conference, San Diego, California, USA, pp. 1366-1370 (1999).

10. Chang, W.J. and Sun, C.C., "Fuzzy Controller Design for Nonlinear TORA Systems," International Journal of Fuzzy Systems, Vol. 2, No. 1, pp. 60-66 (2000).

11. Chang, W.J., Sun, C.C. and Fun, C.C., "Discrete Output Fuzzy Controller Design for Achieving Common Controllability Gramian," Asian Journal of Control, Vol. 2, No. 4, pp. 284-289 (2000).

12. Chang, W.J., Sun, C.C. and Fuh, C.C., "Continuous Output Feedback FuzzyController Design with A Specified Common Controllability Grammian," International Journal of Fuzzy Systems, Vol. 3, No. 1, pp. 356-363 (2001).

13. Chang, W.J., "Model-Based Fuzzy Controller Design with Common Observability Gramian Assignment", ASME, J. Dynamic Systems, Measurement and Control, Vol. 123, No. 1, pp. 113-116 (2001).

14. Nesterov, Y. and Nemirovski, A., Interior Point Polynomial Methods in Convex Programming: Theory and Application, SIAM Books, Philadelphia (1994).

\section{船舶動態位置系統之模糊控制}

張文哲陳國章葉怡麟

\section{國立台灣海洋大學輪機工程系}

摘 要

在本篇論文中, 我們將考虑船舶動態位置系統 (DPSS) 的控制問題。此一問題將被以一個非線性控 制設計的形式來討論, 因爲利用船尾螺旋槳來操控船 舶動態位置系統時, 此一模組將會以非線性的行爲在 縱移、横移、平擺等三個自由度中交錯呈現。本論文 中, 船舶動態位置系統將被模組化成一個TakagiSugeno (T-S) 模糊模型。運用線性迴授控制器設計技 術, 我們將爲 $\mathrm{T}-\mathrm{S}$ 模糊模型化之船舶動態位置系統設 計一個非線性的模糊控制器。最後, 電腦模擬的結果 將用來驗證此一模糊控制方法的實用性。 